\title{
A Comparative Study of the Picture Of Dorian Gray and Its Two Persian Translations in Terms of Cohesive Devices
}

\author{
Elaheh Pirmoradian \\ Graduate School, Islamic Azad University, Shahreza Branch, Isfahan, Iran \\ Email: Eleheh.Pirmoradian@yahoo.com \\ Hossein Vahid Dastjerdi
}

Corresponding author, Graduate School, Islamic Azad University, Shahreza Branch, Isfahan, Iran Email: h_vahid@yahoo.com

\author{
Doi:10.5901/mjss.2014.v5n20p2373
}

\begin{abstract}
Having considered the importance of cohesion in producing a fluent and meaningful text, this study attempts, based on Halliday and Hassan (1976) 's model of cohesion, to compare the English text The Picture of Dorian Gray (Oscar Wilde, 1982) with its two Persian translations by Tahami (2013) and Mashayekhi (2008), to investigate the strategies applied by the two translators in transferring cohesive devices, and to scrutinize the effects of the translators' choices on the transference of the intended meaning to the target language. To this purpose, the cohesive devices (reference, substitution, ellipsis, conjunction and lexical cohesion) of the source text were identified and compared with those in the target texts. These devices were compared intralingually between the two target texts as well. The results of this quantitative and descriptive study revealed that there is not a one-to-one relationship between the source text and target texts in terms of cohesive devices due to the grammatical differences between the two languages and the deletion or addition of some information to the target text to convey the meaning. However, such differences do not damage the transference of the intended meaning to the target language. Also, it was shown that the patterns of use of cohesive devices, except the substitution element, are not the same in the two target texts either, because of stylistic or other differences. These findings require more attention on the part of translators when dealing with these devices which can finally will lead to higher quality renderings.
\end{abstract}

Keywords: Coherence, Cohesive Devices, Reference, Substitution, Ellipsis, Conjunction, Collocation and Reiteration.

\section{Introduction}

It is generally believed that a text whether written or spoken is only meaningful when the various segments are brought together to make a unified whole. Osisanwo $(2005$, p. 31) remarks that a text is said to be cohesive when the linguistic means by which a text function is held together as a single unit. Halliday and Hasan (1976) make a detailed classification of the cohesive devices in English. These authors distinguish between grammatical and lexical cohesion. According to them, grammatical cohesion embraces four different devices: reference, substitution, ellipsis and conjunction. Lexical cohesion embraces reiteration and collocation.

According to Lotfipur (1992), a translator should attempt to make an adjusted translation which is equivalent to the original in terms of cohesive devices (grammatical and lexical). The main idea involved here is 'the equivalent devices', which means devices prevalent in TL text, not the same devices as in SL text. As Lotfipur, Larson (1984) believes that "a one-for-one translation of cohesive devices in TL will almost certainly distort the meaning intended by the original author" (p. 394). Therefore, she points out that the translator should be fully aware of the fact in practice. In literature, however, shifts in types of 'cohesive ties' through translation may alter the central functions of cohesive 'markers' (devices) drastically (Venuti, 2004). As a result, translation of a literary work must be cautiously performed lest the use of wrong devices in the TL disturb the communication and likely distort the message.

Thus, based on what mentioned above, a translation to be communicative must observe the cohesive devices of the target language (reference, substitution, ellipsis, conjunction, reiteration and collocation), and not that of the source language because each language differs from another language in its style in connecting words and sentences together, and the cohesive devices and the rules governing them in order to create a text, depend greatly on the nature of that language. So, a translator who bridges two languages should do his/her best to transfer the meaning of the source text to 
the target text as completely as possible. This goal cannot be achieved just by finding proper equivalents to the words and ignoring the difference between languages makes the translated text a collection of words in awkward and unnatural arrangements without conveying its intended meaning.

Since the actual concern of translator is to primarily transfer the real content of the source text, any failure in producing a coherent body will hamper the communication and the content consequently. This problem becomes more serious when the text is a great literary masterpiece and the content is ethical, as the source text under investigation in this study. Thus, translating such a text demands special attention on the part of the translator so that the translated text would be as smooth and cohesive as the original

Therefore, conducting an investigation on the cohesive style in the source and target languages, especially in the case of literary genres and narrative text types, is of high value in translation and translation studies. This study, following previous investigations about cohesion, attempts, based on Halliday and Hassan (1976) 's model of cohesion, to compare an outstanding English novel, The Picture of Dorian Gray by Oscar Wilde (1982), with its two Persian translations in order to investigate the strategies applied by translators to translate cohesive devices and to scrutinize the effects of the translator 's choices on the transference of the intended meaning to the target language.

The findings of this study can be used for pedagogical and translational purposes. The study can actually yield some solutions for appropriate translation of cohesive devices from English into Persian. It can also help to identify the reliability and practicality of Halliday and Hasssn (1976) 's taxonomy in analyzing cohesive ties and cohesion in general.

\section{Background of the Study}

Halliday (1978) notes that we cannot discuss cohesion without mentioning 'text', 'texture' and 'tie'. Brown and Yule (1989) define text as the verbal record of a communicative event. Scholars such as Vandijk (1972), Gutwinsk (1976), Beaugrande and Dressler (1981) claim 'text' has to do with the principles of connectivity which bind a discourse (spoken or written text) together and force co-interpretation. Fowler (1991) states that, "a text is made up of sentences, but there exist separate principles of text- construction, beyond the rules of making sentences" (p. 59). Hatim and Mason (1990) believe that the text is a set of mutually relevant communicative functions, structured in such a way as to achieve an overall purpose.

The word 'text' is generally used in linguistics to refer to any passage spoken or written of whatever length, that forms a unified whole as opposed to a collection of unrelated sentences. This distinction goes to show that there are certain features which are characteristics of texts. According to Halliday and Hassan (1976) a text has three characteristics:

1. A text may be spoken or written, prose or verse, dialogue or monologue.

2. A text is a unit of language in use.

3. A text is regarded as a semantic unit (p. 2).

Halliday and Hassan then point out that "the concept of texture is entirely appropriate to express the property of being a text. A text has texture and this is what distinguishes it from something that is not a text" (ibid). In their opinion certain linguistic features in a passage, i.e. cohesive devices (reference, substitution, ellipsis, conjunction, reiteration and collocation), contribute to its total unity and giving it texture. In other words, what gives texture to a text is the cohesive ties which it contains.

Cohesion and coherence, as Bell (1993) proposes, are two constituent elements of texture. If the coherence in a text is not well-kept, the reader cannot understand the intended meaning. Thus, a text must be cohesive as well as coherent. The coherence of a text is helped by the proper use of cohesive devices.

The theory of cohesion in English proposed by Halliday and Hassan (1976) and Halliday (1994) has made a significant contribution to the understanding of cohesion and, to a certain extent, coherence of English texts. The theory accounts for the relationship between the different elements of a text so as to enable the reader or listener to derive meaning from the text. Without cohesion a text may be fragmented and lose its meaning. Cohesion makes a text consistent, so that ideas can easily be followed.

According to Baker (1993), cohesion is the network of lexical, grammatical and other relations which provide links between various parts of a text (p. 180). She adds that discourse structure in any language will evidently be collapsed when the series of the sentences in the structure are put together without firm linkage that is cohesion; just as the bricks of a building would be fallen down when there is no cemen, or at least enough, to stick them together. 


\section{Research Questions}

Based on what was stated above, the following questions were addressed in this study:

1. What translation strategies have been used to properly render cohesive devices in the two Persian translations of Oscar Wilde 's The Picture of Dorian Gray?

2. To what extent have the employed strategies affected the target texts in terms of meaning?

\section{Methodology}

\subsection{Materials}

The English novel chosen as the source text for the purpose of this study is The Picture of Dorian Gray by Oscar Wilde (1982), including 20 chapters in 210 pages. It was first published in 1891. This short novel is the story of one beautiful innocent young man's seduction, moral corruption and eventual downfall. It's an interesting combination of elements written in a sort of high literary mode with ornate, self-conscious artistic language and heightened sense of style.

Two translations of The Picture of Dorian Gray by Mashayekhi (2008) and Tahami (2013) were chosen for comparison. To this purpose, out of the whole content of the source text, i.e. 20 chapters, ten chapters were selected randomly, which constitute 110 pages of the source text--54\% of the whole book.

\subsection{Theoretical Framework of the Study}

Although some researchers have identified several types of cohesion (Brown \& Yule, 1983; Cook, 1989; McCarthy, 1991; Renkema, 1993), Halliday and Hassan's (1976) cohesion framework was adopted by the researchers in this study due to the comprehensiveness of its well-known taxonomy.

Halliday and Hassan in their book, Cohesion in English (1976), divided cohesive devices, as mentioned before, into: reference, substitution, ellipsis and conjunction (grammatical cohesive devices), and reiteration and collocation (lexical cohesive devices).

Reference, as the first category of grammatical cohesive devices, involves the use of pronoun articles or adverbs to refer back or forward to an item mentioned in the linguistic or situational text. There are three types of reference: personal, comparative and demonstrative reference. Substitution is the replacement of one item by another. It is a relation in the wording rather than in the meaning. Ellipsis, on the other hand, is the idea of omitting some parts of sentences on the assumption that an earlier sentence will make clear the meaning. Conjunctions are words or phrases that indicate how what is to follow is systematically connected to what has gone before in the text.

Lexical cohesion is established through the structure of lexis or vocabulary. Lexical cohesion encompasses reiteration and collocation. Reiteration simply means repetition of a lexical item or the occurrence of synonyms of some kind in the context reference. That is, where the two occurrences have the same Reference. Reiteration manifests in three ways: supperordinate / hyponym, synonym or near synonym. Collocation is achieved through the association of lexical items that regularly occur. It also involves pairs of words drawn from the same order series.

\subsection{Procedures}

To conduct the present study, the following steps were taken. Out of the whole content of The Picture of Dorian Gray (20 chapters), ten chapters (chapters $1,3,6,7,9,11,14,15,17$, and 19) were selected randomly. In the two Persian translations, corresponding chapters were focused and examined in terms of cohesive devices, namely; reference, substitution, ellipsis, conjunction, reiteration and collocation according to Halliday and Hassan (1976)'s framework of cohesion. Then, the instances of the above mentioned cohesive devices in the source text and their equivalents in each of the target texts were identified. In the next step, the frequency of identified instances of the cohesive devices for the source text and each of the target texts were counted and tabulated.

Finally, on the basis of the collected data, the source text and each of the target texts were compared and contrasted with each other, followed by the comparison of the two target texts with each other, to find the strategies applied in the transference of cohesive devices from English into Persian, and to measure the extent of the effect of the translators' choices on the transference of meaning to the target language. 


\section{Data Analysis and Results}

For the sake of brevity, just one example for each of the mentioned cohesive devices is provided in this section, followed by summarizing the collected data and the results in a number of tables.

\subsection{Reference}

ST: In the center of the room, clamped to an upright easel, stood the full-length portrait of a young man of extra ordinary personal beauty, and in front of it, some little distance away sitting the artist himself.

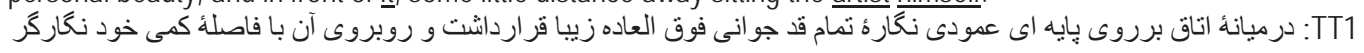

IDar miyaneye otaq bar rooye payehi amoodi neqareye tamam qadde javani foqoladeh ziba qarar dasht va bar rooye aan baa faseleye kami xode negargar neshasteh bood.I

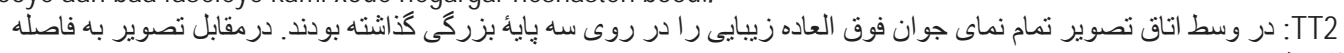
boodand.I

IDar vasate otaq tasvire tamam nemaye javane foqoladeh zibai raa dar rooye se payeye bozorgi gozashteh

Analysis: in the ST, Wilde has applied the personal pronoun it to refer to the portrait and the personal reflective pronoun himself to refer to the artist to create the intended cohesion in the text. Accordingly, Tahami has applied the same strategy as in the ST by using آن/aan/ as equivalent for it and خود/xod/as equivalent for himself. But Mashayekhi has omitted the cohesive devices it and himself.

Table 1 shows the frequency of references used by Wilde and by Tahami and Mashayekhi in the selected parts of the ST and the two TTS.

Table 1. Frequency of References used in the ST and TTs.

\begin{tabular}{|c|c|c|c|}
\hline \multirow{2}{*}{ Cohesive Device } & \multicolumn{3}{|c|}{ Reference } \\
\cline { 2 - 4 } & Wilde & Tahami & Mashayekhi \\
\hline Total Frequency & 6960 & 3760 & 4114 \\
\hline
\end{tabular}

\subsection{Substitution}

ST: You do many things in the world to gain a reputation. As soon as you have one, you seem to want to throw it.

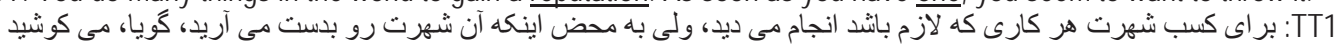
تا به دورش بندازيد.

/Baraye kasbe shohrat har kari ke lazem bashad anjam midid, vali be mahze in ke aan shohrat ro be dast miarid, gooya, mikooshid taa be doorash bendazid.I

$$
\text { TT2 هينكه دور ان شهرت و افتخارشروع شد، مى خو اهيد هر طور شده از آن فرار كنيد. }
$$

/Haminke dourane shohrat va eftexar shoroo shod, mixahid har tour shodeh az aan farar konid.I

Analysis: In the ST, one as nominal substitution refers to reputation. None of the translators have considered the cohesive device of the ST, due to the repetition of شهرت/Shohrat/ in the second sentence of TT1 and using آن /aan/ in TT2.

Table 2 shows the frequency of substitutions used in the selected parts of the ST and TTs.

Table 2. Frequency of Substitutions used in the ST and TTs.

\begin{tabular}{|l|c|c|c|}
\hline \multirow{2}{*}{ Cohesive Device } & \multicolumn{3}{|c|}{ Substitution } \\
\cline { 2 - 4 } & Wilde & Tahami & Mashayekhi \\
\hline Total Frequency & 66 & 43 & 43 \\
\hline
\end{tabular}

\subsection{Ellipsis}

ST: "I quite forget what I said ", smiled Lord Henry, "was it all very bad"?

"Very bad indeed". 


$$
\text { bا }
$$
goftam?!

IMan har aanche ro goftam be kolli Faramoosh kardam. Chetour? Lord Henry labxandi zad, chiz haye badi

$$
\text { -Besyar bad/ }
$$

$$
\text { TT2 - من - منى دانم جه كَتتم، مكر خيلى بد و بير اه بود؟؟ }
$$

IMan nemidanam che goftam, magar xeili bad o birah bood?

-Besyar bad/

Analysis: Here, very bad is clausal ellipsis for it was very bad. Both translators have applied the model of ST to establish cohesion and have thus correctly translated the clausal ellipsis by using بسيار بد /besyar bad/ as equivalent for it.

Table 3 shows the frequency of ellipsis used by Wilde,Tahami and Mashayekhi.

Table 3. Frequency of Ellipsis used in the ST and TTs.

\begin{tabular}{|c|c|c|c|}
\hline \multirow{2}{*}{ Cohesive Device } & \multicolumn{3}{|c|}{ Ellipsis } \\
\cline { 2 - 4 } & Wilde & Tahami & Mashayekhi \\
\hline Total Frequency & 103 & 63 & 57 \\
\hline
\end{tabular}

\subsection{Conjunction}

ST: Besides, Dorian, don't deceive yourself.

IAz hame mohem tar, Dorain xodet ro farib nadeh.I

$$
\text { TT1 : از همه مهم تر، دوريان خودت رو فريب نده. T1 }
$$

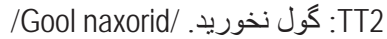

Analysis: Besides, in this case, is additive conjunction. Tahami has translated the conjunction into از همه مهم تر /az hame mohem tar/ which seems to be an appropriate equivalent for besides, but Mashayekhi has missed the intended cohesion of the ST by omitting the conjunction.

Table 4 below shows the frequency of conjunctions applied by Wilde, Tahami and Mashayekhi.

Table 4. Frequency of Conjunctions used in the ST and TTs.

\begin{tabular}{|c|c|c|c|}
\hline \multirow{2}{*}{ Cohesive Device } & & \multicolumn{3}{c|}{ Conjunction } \\
\cline { 2 - 4 } & Wilde & Tahami & Mashayekhi \\
\hline Total Frequency & 1260 & 1071 & 56 \\
\hline
\end{tabular}

\subsection{Lexical Cohesion}

ST: People go about nowadays saying things against one's back that are absolutely and entirely true.

$$
\text { TT1 }
$$

I mardom rah mioftand va chiz hayi poshte sare ensan migand ke sad dar sad va kamelan haqiqat dareh.I

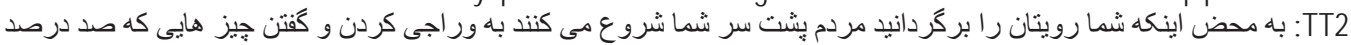
راست است.

Ibe mahze in ke shoma rooyetan ra bargardanid mardom poshte sare shom shoroo mikonand be verraji kardan va goftane chiz hayi ke sad dar sad rast ast.l

Analysis: In this case, absolutely and entirely make reiteration lexical cohesion of synonym relation. Tahami has correctly translated reiteration of the ST by providing صد در صد و كاملا/sad dar sad va kamelan/ as equivalent for the cohesive device. But Mashayekhi has ignored this lexical cohesion by omitting it.

Table 5 below shows the frequency of conjunctions applied by Wilde and the two translators.

Table 5. Frequency of Lexical Cohesion used in the ST and TTs.

\begin{tabular}{|c|c|c|c|}
\hline \multirow{2}{*}{ Cohesive Device } & \multicolumn{3}{c|}{ Lexical Cohesion } \\
\cline { 2 - 4 } & Wilde & Tahami & Mashayekhi \\
\hline Total Frequency & 1260 & 1071 & 856 \\
\hline
\end{tabular}




\section{Results}

The following table summarizes the results of the analyzed data discussed above, illustrating the frequency of each of the cohesive devices (reference, substitution, ellipsis, conjunction and lexical cohesion) in the selected parts of the source text and the frequency of these devices in the two corresponding target texts. As shown in Table 6, cohesive devices have a higher frequency of use in comparison with the two TTs, and the patterns of these devices, except in the case of substitution element, are not the same in the two TTs either.

Table 6. Frequency of Cohesive Devices used in the ST \& TTS

\begin{tabular}{|l|c|c|c|}
\hline Types of Cohesion & ST & TT1 & TT2 \\
\hline Reference & 6960 & 3708 & 4114 \\
\hline Substitution & 66 & 43 & 43 \\
\hline Ellipsis & 103 & 63 & 57 \\
\hline Conjunction & 1260 & 1071 & 856 \\
\hline Lexical cohesion & 379 & 330 & 251 \\
\hline Total Frequency of Cohesive Devices & 8768 & 5215 & 5321 \\
\hline
\end{tabular}

\section{Findings and Discussion}

In order to answer the research questions of the study, after identifying the cohesive devices of the source text, these cohesive devices were compared with those in the two corresponding target texts. The research questions were about the strategies the two translators, Tahami (2013) and Mashayekhi (2008), have used in rendering such cohesive devices as reference, substitution, ellipsis, conjunction, and lexical cohesion, i.e. collocation and reiteration; and also the effects of the translator 's choices on the transference of meaning to the target text.

In the case of reference, as shown in Table 1, there was a considerable difference in the frequency of the references in the ST and TTs. This is to a large degree because of grammatical differences between English and Persian languages. English requires the presence of subject at the beginning of all sentences. This feature forces the language to use the reference mechanism more extensively, while in Persian the subject can be interpreted from the verb by itself, and thus, the subject which is a pronoun most of the times, can be omitted in Farsi. Besides, in English, there is a special singular pronoun for each gender, male and female, but in Persian this is not the case. The other source of this variation is that in Persian an exact and stable equivalent for the article the does not exist, which according to Halliday and Hassan (1976) is a demonstrative pronoun and used to a large degree in English sentences. Even the pattern of reference in the two TTs is not the same.

In the case of substitution, as indicated in Table 2, there is not a one-to-one relationship between the ST and TTs. This is due to the fact that sometimes translators have added some information or repeated the same part of the sentence to convey the meaning to the TT. However, the pattern of substitution is the same in the two TTs.

According to Table 3, in the case of ellipsis, again there is rather a big difference between the frequency of this cohesive device in the ST and TTs because of the repetition of some unnecessary information in the TT which has been omitted in the ST. Even in the two TTs, the pattern of ellipsis is different.

As for conjunction, as illustrated in Table 4, there is not a one-to-one relationship between the ST and TTs and even between the TTs as well. Most of the conjunctions were transferred to the TTs (but not literally translated in all instances) while in several cases some conjunctions especially and at the beginning of the independent sentences have been omitted in the TTs.

In the case of lexical cohesion, as shown in Table 5, the patterns of collocation and reiteration are different in the ST and TTs and even between the TTs. This difference is because of the fact that some reiterations of the ST have not been considered by the translators in the two TTs. On the other hand, there is less variation in the collocation patterns of the ST and TTs in comparison with reiteration patterns.

To sum up, on the one hand, there is not a one-to-one relationship between the ST and TTs in the use of cohesive devices because of the grammatical differences of the two languages. On the other hand, even the target texts, except in the case of substitution, have not followed the same patterns in the use of cohesive devices because of the fact that each translator has applied his own taste, style of writing and choice of words, and even, the attention to these devices may have varied from one translator to another.

The findings of the present study reinforce those of previous researches which have investigated Persian-English 
literary translations in terms of cohesive devices. For example, Khanzad (2007) and Dastjerdi \& Taghizadeh (2006) show the same results in the case of comparison of cohesive devices in English and Persian languages. Dastjerdi \& Taghizadeh in a similar study compared a Persian literary text, Gulistan, with its two English versions in terms of cohesive devices. The results of their study revealed that there was a considerable difference between the ST and TTs in the use of cohesive devices. Actually, the present study and its predecessors go side by side to the effect that awareness of inevitable differences which show the lack of one-to-one relationship between English and Persian languages concerning cohesive devices helps to choose appropriate equivalents in order to translate from each of these languages into another.

\section{Concluding Remarks}

A text in order to be communicative and meaningful to the receiver of any discourse, must be cohesive or, in other words, hanging together. This feature is provided by the use of cohesive devices including, reference, substitution, ellipsis, conjunction and lexical cohesion, i.e. reiteration and collocation in the text. A translation to be communicative has to observe the cohesive devices of the target language and not that of the source language. This is due to the fact that each language differs from another in its techniques in connecting words and sentences together, and that the rules governing cohesive devices are not the same in all languages, but vary from one language to another depending on the nature of the language.

The present study considered the translation of cohesive devices, based on Halliday and Hassan's (1976) model of cohesion, in the two Persian translations of an English novel, i.e. The Picture of Dorian Gray. Based on the obtained results, it can be concluded that there is not a one-to-one relationship between the ST and TTs, nor between the two TTs. This is because of the different grammatical systems of the two languages and the fact that even within one language, two translators may apply different techniques to deal with cohesive devices depending on their specific style of writing, taste, experience of the translation task, etc. Mashayekhi has used more references compared with Tahami, while both of them have used fewer references than the Wilde. But this difference has not disturbed the transference of the intended meaning to the TTs by the translators. Even in some rare cases, cohesion in the TTs is much more than that of the ST. In the case of substitution, both translators have applied the same pattern but used fewer substitutions in comparison with the ST. In the case of ellipsis, Tahami has used more ellipsis than Mashayekhi and again both of them have used fewer ellipsis than Wilde. The difference between the patterns of substitution and ellipsis in the ST and TTs which is due to the addition of some extra information to the TT in order to convey the meaning, has not affected the transference of meaning, but more attention to these devices, as it was obvious in Tahami 's translation, has led to a translation of higher quality. In the case of conjunction, none of the translators have considered some of the conjunctive elements, and in some cases, they have changed the conjunctions of the ST. Tahami has used more conjunctions, i.e. in comparison with Mashayekhi. Again, this has not hampered the transference of meaning by the translators. Finally, the number of lexical cohesions applied in the TTs, were less than the ST and Tahami has provided more lexical cohesions in comparison with Mashayekhi in his translation. Actually, both translators, in this case, have successfully transferred the meaning of the ST, though they have not followed the same pattern as in the ST. It can be noted that more attention to collocation and reiteration patterns of the ST has led to more fluent and higher quality translation by Tahami.

\section{References}

Baker, M. (1993). Corpus linguistics and Translation Studies: Implications and Applications. In Baker, M. et al. (Ed). Text and Technology: In Honour of John Sinclair. Amesterdam: John Benjamin.

Bell, R. T. (1993). Translation and Translating. London \& New York: Longman.

Beaugrande, R. \& Dressler, W. (1981). Introduction to Text Linguistics. London: Longman.

Brown, G. \& Yule, G. (1983). Discourse Analysis. Cambridge, UK: Cambridge University Press.

Brown, G. \& Yule, G. (1989). Discourse Analysis. Cambridge, UK: Cambridge University Press.

Cook, G. (1989). Discourse. Oxford, UK: Oxford University Press.

Fowler, R. (1991). Language in the News: Discourse and ldiology in the Press. London \& New York: Ruotledge.

Gutwinski, W. (1976). Cohesion in Literary Texts. The Hague: Mouton.

Halliday, M. A. K. (1987). On the Notion of a Text. Humburg: H. Buske.

Halliday, M. A. K. (1994). Introduction to Functional Grammar. London: Arnold.

Halliday, M. A. K. \& Hassan, R. (1976). Cohesion in English. London \& England: Longman.

Hatim, B. \& Mason, I. (1990). Discourse and the Translator. London: Longman.

Khanzad, O. (2007). A Comparative Study of Cohesion in Translation from Persian into English: A Case Study of Sadi 's Gulistan. (Master 's Thesis). Retrieved from Dissertationtopic.net. Doc H 315. 
Larson, M. (1984). Meaning- Based Translation: A Guide to Cross- Language Equivalence.

Lenham, New York \& London: University Press of American

Lotfipur Saedi, K. (1992). An Introduction to Principles of Translation. Tehran: Markaze nashre Daneshgah.

Mashayekhi. R. (2008). The Picture of Dorian Gray. Tehran: Jami. (Original work published 1982)

McCarthy, M. (1991). Discourse Analysis for Language Teachers. Cambridge, UK: Cambridge University Press.

Osisanwo, W. (2005). Introdution to Discourse Analysis and Pragmatics. Lagos: Femulus Fetop Publisher.

Renkema, J. (1993). Discourse Studies. Amesterdam \& Netherland: John Benjamin.

Tahami, A. (2013). The Picture of Dorian. Tehran: Negah. (Original work published 1982)

Vahid Dastjerdi, H. \& Taghizadeh, S. (2006). Application of Cohesive Devices in Translation: Persian and their English Translations in Contrast. Iranian Journal of Translation Studies, 3, 57- 68.

Vandijk, A. T. (1972). Text and Context Explorations in the Semantics and Pragmatics of Discourse. London: Longman.

Venuti, L. (2004) (ed.). Translation Studies Reader, $2^{\text {nd }}$ ed. New York \& London: Routledge.

Wilde, O. (1982). The Picture of Dorian Gray. New York: Random House. 